\title{
Futbolistas o delincuentes: polarización de la imagen televisiva de los inmigrantes en el género informativo
}

\author{
Vanessa RodRÍGUEZ BREIJO \\ Universidad San Jorge (Zaragoza) \\ vrodriguez@usj.es
}

Recibido: 1 de septiembre de 2011

Aceptado: 6 de febrero de 2012

\begin{abstract}
Resumen
Los inmigrantes son representados de dos formas muy diferentes y opuestas en el género informativo de la televisión. En la primera suelen ser deportistas de elite o artistas con una gran seguridad laboral, famosos, pacíficos, cumplidores de la ley y sin problemas de integración en lo socioeconómico. En la segunda, por el contrario, no son famosos; aparecen de forma habitual en la sección de sucesos; se vinculan frecuentemente con las actividades delictivas, ya sea como agresores o como víctimas; tienen peores categorías laborales y su precariedad es mayor. Estos dos polos opuestos en la vida real son colectivos minoritarios, que en este medio se encuentran sobrevalorados por su constante aparición en las noticias y reportajes. Esta imagen sesgada podría no estar favoreciendo la integración de las personas de origen extranjero.
\end{abstract}

Palabras clave: Televisión, programas informativos, inmigrantes, análisis de contenido, delincuencia.

\section{Football players or criminals: polarization of the TV image of immigrants in the informative genre}

\begin{abstract}
Immigrants are represented in two very different and conflicting ways in the genre of television. In the first way, immigrants often are elite athletes or artists with a great job security, famous, peaceful, lawabiding and without trouble in their socioeconomic integration. In the second way, by contrast, are not famous and appear regularly in the accidents and crime reports; often linked to criminal activities, either as attacker or as victims; have worse labour categories and their scarcity of resources is greater. These two polar opposites in real life are two minority groups, that in the television are overvalued by their constant appearance on the news and reports. This image is biased and maybe it isn't contributing the integration of people of foreign origin.
\end{abstract}

Keywords: Television, news program, immigrants, content analysis, crime.

Referencia normalizada: RODRÍGUEZ BREIJO, Vanessa (2012): "Futbolistas o delincuentes: polarización de la imagen televisiva de los inmigrantes en el género informativo". Estudios sobre el mensaje periodístico, vol. 18, núm. 2 (julio-diciembre), págs.: 595-612. Madrid, Servicio de Publicaciones de la Universidad Complutense.

Sumario: 1. Los medios y la construcción de la realidad. 2. Los inmigrantes en los medios de comunicación. 3. Metodología. 4. La fama como elemento definidor. 5. Cómo son los inmigrantes en el género informativo. 6. La importancia de los inmigrantes y sus características en los programas informativos. 7. Valoración de los inmigrantes en el género informativo. 8. Temas frecuentemente relacionados con los inmigrantes. 9. Conclusiones. 10. Referencias bibliográficas.

\section{Los medios y la construcción de la realidad}

El poder de los medios de comunicación para modelar la forma en que sus audiencias perciben la realidad ha acaparado la atención de los estudios sobre los efectos desde la década de los setenta del siglo pasado hasta la actualidad. Estas investigaciones se han deslindado de la tradicional pregunta sobre la influencia mediática a corto plazo 
sobre actitudes y comportamientos, para interrogarse acerca de cómo poco a poco y de forma progresiva la exposición continua a los contenidos de la prensa, la radio y la televisión contribuyen a configurar una determinada concepción acerca de la realidad social (VILCHES, 1993).

Pero la realidad reflejada por los medios no es transparente, porque en el proceso de comunicación masiva entran en juego los criterios selectivos de los emisores. La sociedad es muy compleja y es imposible hacer una representación total de ella y de sus problemas; de allí que los medios determinen qué partes de la realidad serán transmitidas. Una consecuencia de ello es que a los grupos y categorías sociales se les atribuyen características arbitrariamente fijadas por los comunicantes sobre la realidad. Esta selección opera como mediación de las percepciones de la audiencia, en otras palabras, es un filtro entre la audiencia y la realidad. Uno de los resultados de este proceso es la creación de una idea de la sociedad que no necesariamente corresponde con la realidad; esto es, un cuadro de representaciones que afectarán profundamente las percepciones de las audiencias de los medios (RODA FERNÁNDEZ, 2001).

En el género informativo, los criterios selectivos de la realidad que se va a representar se expresan no solo en la elección de determinados hechos noticiosos, sino en la escogencia del material y su disposición en la pieza periodística final, que configuran un determinado enfoque en el que se destacan unos elementos y se minimizan otros. Asimismo, la prioridad que se le concede a algunas noticias y a datos específicos dentro de cada una de ellas tiene un componente interpretativo que rebasa los límites de la objetividad más aséptica. Y aunque la audiencia no es pasiva ante los contenidos mediáticos, los espectadores no siempre tienen todos los elementos necesarios para realizar un análisis completo de las versiones que reciben sobre un hecho y lo interpretan a partir de los datos que aparecen en el relato, ignorando los demás condicionantes y circunstancias extraperiodísticas (SoENGAS, 2008).

Esta imagen de la realidad ofrecida por los medios, condicionada por múltiples mediaciones y efectivamente sesgada, resulta sin embargo un factor determinante en la construcción de la idea del mundo que hacen las audiencias. Así lo han demostrado los estudios empíricos de de Maxwell McCombs y Donald Shaw, en relación con la hipótesis de la función de establecer la agenda pública; de Elisabeth Noelle Neumann, con sus conceptos de tematización, clima de opinión y espiral del silencio; y de George Gerbner, con su teoría del cultivo (RODA FERNÁNDEZ, 2001).

Las investigaciones de George Gerbner y la Escuela de Annenberg demostraron que aquellos espectadores que veían más horas de televisión tendían a percibir el mundo real de una forma más parecida a como lo refleja la televisión en sus mensajes recurrentes (MORGAN y SHANAHAN, 2010), tomando en cuenta, por supuesto, que esta influencia no ocurre en un vacío social e interacciona con otras instituciones y grupos de referencia (SHANAHAN y Morgan, 1999).

Por su parte, la hipótesis sobre la función de los medios de establecer la agenda pública llama la atención hacia la equivalencia entre el énfasis con que la prensa, la radio y la TV tratan determinados problemas, y la importancia que los receptores de la comunicación atribuyen a esos problemas (RODA FERNÁNDEZ, 2001). Incluso plantea que los medios construyen la agenda pública a través de dos mecanismos: estable- 
ciendo qué temas debe pensar la audiencia (primer nivel) y sugiriendo cómo debe pensar en esos asuntos (segundo nivel). Los medios encuadran las imágenes de la realidad de una forma determinada que suele seguir un patrón. De esta forma proporcionan los marcos de referencia que usa la audiencia para interpretar y discutir los asuntos públicos (HuMANES, 2001).

En un planteamiento similar, Elisabeth NoELLE-NeumanN (1995) plantea que la homogeneidad y concordancia de criterios por parte de los informantes de los medios de comunicación, al aplicarse de manera común al juicio de los eventos públicos, hace que esa imagen de la realidad parezca la verdadera o por lo menos la más aceptada. Por esa razón el receptor individual tiende a asumir como propia esa versión del mundo y de los acontecimientos, principalmente por miedo al aislamiento y al rechazo que ocasionaría hacer pública otra pauta interpretativa.

De este modo, puede afirmarse que existe un acuerdo común entre las teorías más aceptadas actualmente al ubicar como consecuencia más importante de la exposición a los medios la creación de nociones compartidas acerca de la realidad social. Esta construcción de una forma común de percibir y entender el mundo es un efecto de la exposición continua y sostenida, y proviene de la concordancia y homogeneidad entre las representaciones de la sociedad que se transmiten en los distintos medios de comunicación.

\section{Los inmigrantes en los medios de comunicación}

El acuerdo tácito sobre la influencia de los medios en la construcción de la realidad social ha motivado que en España se haya incrementado la inquietud acerca de los contenidos mediáticos relacionados con la inmigración, a raíz del aumento de la entrada de personas de origen extranjero los últimos años. Con especial incidencia han surgido preguntas sobre la responsabilidad de esos contenidos en la discrepancia entre el aporte real de los inmigrantes a la sociedad y la valoración que de ellos hace la población española. En este sentido, el último estudio del Centro de Investigaciones Sociológicas señala que más de tres cuartas partes de los españoles considera elevado o excesivo el número de personas pertenecientes a este colectivo (CIS, 2009), mientras un tercio de los mismos relaciona la inmigración con el aumento de la delincuencia y la inseguridad (CEA D'AnCona y VAlles Martínez, 2008).

En la configuración de esta imagen de los inmigrantes vinculados con problemas y usurpando los privilegios de la población nativa, el papel de los medios de comunicación es una idea recurrente de los estudiosos del tema (ZAPATA-BARRERO, 2009; Naïr, 2006; Rostecka, 2005; Pajares, 2005; Garreta Bochaca, 2003; MÁrqueZ DíEZ, 2000, entre otros), que coinciden en otorgar a la prensa, la radio y la televisión la capacidad de crear imágenes distorsionadas sobre las personas que provienen de otros países.

La atención hacia esta influencia ha suscitado un creciente número investigaciones sobre la representación mediática de las personas de origen extranjero en los últimos años. Entre las conclusiones a las que han llegado se encuentran: la vinculación entre presencia de inmigrantes y problemas sociales como la delincuencia (RODRÍGUEZ DÍAZ y Mena Montes, 2008; Galán Fajardo, 2006; MuÑIz e Igatua, 2004; Casero RiPoLLÉs, 2003); el énfasis excesivo en la llegada masiva de inmigrantes y la idea de inva- 
sión (SABÉs Turmo, 2010; RodríGuez Borges, 2010; RodríGuez Díaz y Mena Montes, 2008; Merino Arribas, 2008; Pablos Coello y Ardebol Abreu, 2008; Lorite, 2004); el empleo de estereotipos negativos asociados a la imagen del inmigrante (LACALLE, 2008; GALÁN FAJARDO, 2006); la descontextualización histórica, económica, social y personal del abordaje informativo de la inmigración (ARDEBOL ABREU, 2008; García Castaño, Granados Martínez y CAPellán de Toro, 2003); la escasa, aunque creciente, información sobre los procesos de integración de las personas de origen extranjero (MERINO ARRIBAS, 2008; LORITE, 2004); la visión utilitarista de los inmigrantes, por un acento recurrente de su faceta laboral (CASERO RIPOLLÉs, 2003) y la identificación del foráneo con debilidad y subalternidad (ARDEBOL ABREU, 2008).

Con el conocimiento de estos resultados y de las teorías de los efectos a largo plazo de la televisión, nació la inquietud sobre la influencia de esas imágenes sesgadas de los inmigrantes en la disposición de la población autóctona para contribuir a su integración. De allí que surgiera la pregunta de cómo es la representación de este colectivo en ese medio, si es favorecedora de la integración o más bien la dificulta. Esta interrogante dio origen a una tesis doctoral en la que se analizó la representación de las personas de procedencia extranjera en todos los géneros televisivos (RodRíGUEZ BREIJO, 2010) y también suscitó el presente artículo, en el que se exponen únicamente los resultados referentes al género informativo, intentando describir los aspectos más resaltantes de la imagen que proyecta la TV de los inmigrantes en los programas de información.

Dos hipótesis iniciales marcaron el inicio de esta investigación. La primera era que previsiblemente existiría una marcada diferencia entre la representación de los inmigrantes famosos y la de los no famosos, y la segunda que la de estos últimos estaría vinculada a la delincuencia y los problemas sociales, mientras que los personajes públicos tendrían una imagen mayoritariamente positiva.

\section{Metodología}

Se aplicó la técnica del análisis de contenido sobre una muestra representativa de programación televisiva de todos los géneros (incluyendo publicidad), proporcionalmente distribuidos según la audiencia que tenían los distintos programas en Tenerife (TNS, 2008). Para este artículo se extrajeron los resultados correspondientes al género informativo, conformado este por el conjunto de los programas que registran los hechos reales de interés periodístico, en otras palabras, los que "se interesan por los asuntos sociales, políticos o de economía de la actualidad diaria" (BARroso GARCÍA, 1996: 52). Esta condición deriva de que los hechos "acontezcan y se refieran al ahora, o de que ahora se actualice el interés de lo ocurrido en el pasado" (SANABRIA, 1994: 63).

Para distinguir los programas informativos de otros en los que también existía un interés por la actualidad, fue preciso definir la información periodística como aquella que tiene como fin primordial la notificación de un suceso o idea transmitiendo una versión lo más fiel posible de la realidad (BARROSO GARCíA, 1996). De esta forma quedaban excluidos los programas basados en la realidad, pero con elementos de ficción o dramatización. En todo caso, se usó como pauta definidora del género el tratamiento (ficcional o periodístico) que predominara en el programa, puesto que en muchas ocasiones la frontera entre ambos géneros resulta difusa (IMBERT, 2003). 
Dentro del género informativo se incluyeron los noticieros diarios o telediarios, los programas informativos periódicos no diarios y los avances.

El tamaño total de la muestra analizada (incluidos todos los géneros televisivos) fue de 9595 minutos. Este dato fue determinado a través de la fórmula para fijar el tamaño muestral en universos infinitos (de más de 100.000 individuos, en este caso horas): $\mathrm{n}=\mathrm{o}^{2} \cdot \mathrm{p} \cdot \mathrm{q} / \mathrm{E}^{2}$, en la que o es el nivel de confianza, $\mathrm{p}$ y q las varianzas y $\mathrm{E}$ el error muestral (SIERRA BRAVO, 1999). Para este estudio el nivel de confianza fue de dos sigmas, la desviación típica se estableció en un 50\% y el error muestral en un $8 \%$. Sustituyendo estos datos en la fórmula, se obtuvo un resultado de 156 horas, que finalmente se convirtieron en 159,9 horas, para no cortar el final de los últimos programas grabados. La grabación de la muestra se realizó desde el 30 de marzo hasta el 21 de mayo de 2008.

Dentro de esta muestra total, el género informativo ocupó 1786,05 minutos. Se seleccionaron los programas con mayor audiencia en Tenerife: las transmisiones del mediodía y la noche de Antena 3 Noticias (38,26\% del tiempo total de este género), Informativos Tele 5 (20,68\%), Telediario de TVE (17,23\%), Telenoticias de Televisión Canaria (12,72\%); la edición del mediodía Telecanarias de TVE (1,67\%); Informe semanal de TVE (3,37\%); Telediario de fin de semana de TVE (1,67\%); Callejeros de Cuatro $(4,39 \%)$ y el avance informativo del mediodía de Antena 3 Noticias $(0,01 \%)$. Estas proporciones de representación en la muestra fueron determinadas por el lugar que cada programa ocupaba dentro de la medición de audiencia de cada día de la semana. Los minutos que debían analizarse por cada día fueron completados seleccionando en orden decreciente los programas más vistos, hasta llegar al tiempo previsto.

La unidad de análisis que se seleccionó para este estudio fue la secuencia, que puede definirse como "aquel conjunto de acontecimientos que, aunque no se desarrollen todos en el mismo escenario, sí poseen una cierta unidad temática e incluso temporal" (VILlafaÑe y MíngueZ, 1996: 192). En los programas informativos diarios y en los avances, cada pieza periodística (noticia, reportaje, etc.) fue considerada una secuencia. En los no diarios, conformados por varios reportajes largos, se utilizaron las divisiones temáticas existentes dentro de cada pieza.

Se registró en una ficha cada emisión analizada. Asimismo, se rellenó una ficha de análisis por cada secuencia, es decir, por cada unidad de análisis, con la excepción de las secuencias en las que no se mencionaban, aparecían o actuaban inmigrantes, para las cuales se respondió una sola vez (por programa) la ficha.

En este estudio se consideró inmigrante a cualquier persona nacida en el extranjero y/o cuya residencia regular estaba ubicada en el extranjero, que se hubiera trasladado a otro país distinto para fijar allí su residencia. Las personas que nacieron en el país en el que viven actualmente se catalogaron como inmigrantes si residieron fuera de él por un tiempo superior al $25 \%$ de la edad que tienen, siempre que ese período sea mayor a 10 años y que hayan regresado hace no más de 10 años. Se consideraron inmigrantes porque la cantidad de tiempo que han vivido fuera de su país es lo suficientemente significativa como para adoptar expresiones culturales del lugar en el que vivieron esos años y porque tienen el retorno relativamente reciente como para haber olvidado esos posibles cambios culturales ocurridos en el primer proceso migratorio. 
El diseño de la ficha de análisis se configuró a partir de las cuatro dimensiones esenciales que la Escuela de Annenberg halló en sus análisis de los indicadores culturales y que representan vías de acceso para conocer la estructura de las representaciones que transmiten los medios (GERBNER, 1969): lo que hay (presencia y frecuencia de temas), lo que es importante (orden de prioridades que tienen los componentes de un sistema de mensajes), la calificación valorativa de los elementos (cualidades afectivas asociadas con los distintos elementos) y las tendencias de relación entre los elementos (vinculaciones que se establecen entre asuntos diferentes). De esta manera, la ficha de análisis se constituyó de las siguientes partes:

1. Identificación de la unidad de análisis y del programa.

2. Variables relacionadas con la dimensión de lo que hay: este bloque buscaba responder cuál es la frecuencia de aparición de los inmigrantes de origen extranjero en la muestra estudiada. El análisis de estas variables definió también las características de los inmigrantes representados en la televisión: cómo son (sin juicios valorativos manifiestos) y cómo se compone la inmigración de origen extranjero representada en los programas analizados. Por ello las preguntas iban dirigidas especialmente a indagar en las peculiaridades demográficas de los inmigrantes que aparecen, actúan o se mencionan en los diferentes programas de la muestra.

3. Variables relacionadas con la dimensión de lo que es importante: este conjunto de variables definieron qué características de los inmigrantes se enfatizaron en las unidades de análisis. Se determinó qué aspectos de ellos fueron los que se más se resaltaron y de los que más información se ofreció.

4. Variables relacionadas con la dimensión de la calificación valorativa de los elementos: si en las dos dimensiones anteriores se definieron las características de los inmigrantes que aparecieron en los programas de la muestra y cuáles de ellas fueron más importantes, en esta dimensión se prestó atención a cómo fueron calificados los inmigrantes, qué juicios valorativos y qué adjetivos calificativos se les atribuyeron, directa o indirectamente. Se hizo un escrutinio de su actitud y sus comportamientos para conocer en qué medida eran agresivos o pacíficos, autosuficientes o indefensos, sanos o enfermos, cumplidores o quebrantadores de la ley, etc. Al tener cada una de estas características una clara tendencia, positiva o negativa, se pudo determinar si la imagen de los inmigrantes que se transmitió fue buena o mala, y, por tanto, si favorecía la percepción de la inmigración como un fenómeno que aporta beneficios a la sociedad receptora, o como un peligro o una amenaza.

5. Variables relacionadas con la dimensión de las tendencias de relación entre los elementos: describen la presencia o ausencia de relaciones entre determinados conceptos y la aparición o mención de inmigrantes. Se midió con qué frecuencia cuando figuraron inmigrantes, también se habló o se mostraron imágenes referentes a: exceso poblacional, presencia policial, aumento de la inseguridad, crisis económica, enriquecimiento cultural, ayudas humanitarias de la población autóctona, terrorismo, pobreza de los países subdesarrollados y otros conceptos que, al estar unidos al de inmigrante, también definen lo que este significa para la sociedad receptora. 
Una vez analizada la muestra a través de la ficha descrita, los datos obtenidos se importaron al programa SPSS (versión 13) para su tratamiento estadístico. En esta fase se compararon los resultados de los inmigrantes famosos y no famosos, para determinar si había diferencias en la representación de ambos grupos y cuáles fueron.

Las distintas variables que conformaron la ficha de análisis fueron medidas no por su frecuencia (número de unidades de análisis), sino por la suma de la duración de todas las unidades de análisis en las que apareció cada categoría, es decir, por el tiempo total que duró la representación de esa característica particular. Esta decisión estuvo motivada por la disparidad de la duración de las distintas unidades de análisis (secuencias).

\section{La fama como elemento definidor}

Del género informativo se analizaron menos minutos que de los géneros ficción y entretenimiento (1786,05 frente a 4403,4 y 3298,05 respectivamente). Sin embargo, la información obtuvo el segundo lugar en el peso relativo del tiempo en que figuraron inmigrantes, con un $17,38 \%$, muy cercano a la ficción $(19,22 \%)$ y al entretenimiento $(16,74 \%)$. La publicidad fue el que menos minutos ocupó en la muestra $(2057,1)$ y el que tuvo menor porcentaje de tiempo en el que aparecieron o se mencionaron personas de origen extranjero $(3,14 \%)$.

Del tiempo en que figuraron inmigrantes en el género informativo, en la sección en la que más frecuentemente aparecieron, actuaron o se mencionaron personas de origen foráneo fue la de deportes, con un $43,27 \%$, seguida por sucesos $(22,16 \%)$ y cultura y espectáculos $(11,53 \%)$. Estas tres secciones acapararon más de tres cuartas partes del tiempo total de la información, siendo menos significativo el tiempo en que figuraron inmigrantes en la sección de nacionales $(7,93 \%)$, sociedad $(7,65 \%)$, internacionales $(5,49 \%)$, economía $(1,61 \%)$ e información meteorológica $(0,35 \%)$.

En la sección de deportes, así como en la de cultura y espectáculos, existió un predominio de inmigrantes famosos, entendiendo por estos los que son conocidos por el público, los que suelen aparecer en los medios de comunicación y cuyas vidas, o determinados aspectos de ellas, son información de acceso no restringido. De este modo, el tiempo en el que figuraron estos personajes públicos excedió levemente al dedicado a personas carentes de fama (51,29\% frente a 45,86\%). Esta preponderancia de los inmigrantes famosos solo se repitió en el género publicitario, en el que alcanzaron un $57,46 \%$. Tanto en ficción $(0,06 \%)$ como en entretenimiento $(37,15 \%)$ fue mucho menos habitual.

Las secciones en las que más frecuentemente aparecieron o se mencionaron inmigrantes famosos fueron deportes (96,72\% del tiempo total de esta sección) y cultura y espectáculos $(75,57 \%)$. Un 98,12\% de los minutos en que figuraron personajes públicos de origen extranjero en los programas informativos analizados lo hicieron en estas dos secciones.

En cambio los inmigrantes no famosos aparecieron o se mencionaron más de la mitad del tiempo (en el género informativo) en la sección de sucesos $(68,05 \%)$. A esta le siguieron: nacionales $(23,85 \%)$, sociedad $(23,75 \%)$, internacionales $(14,30 \%)$, cultura y espectáculos $(5 \%)$, economía $(4,40 \%)$, deportes $(1,90 \%)$ e información meteorológica $(1,10 \%)$. 
Gráfico 1: Comparación del porcentaje de tiempo en que figuraron inmigrantes no famosos y no famosos en las diferentes secciones de los programas informativos

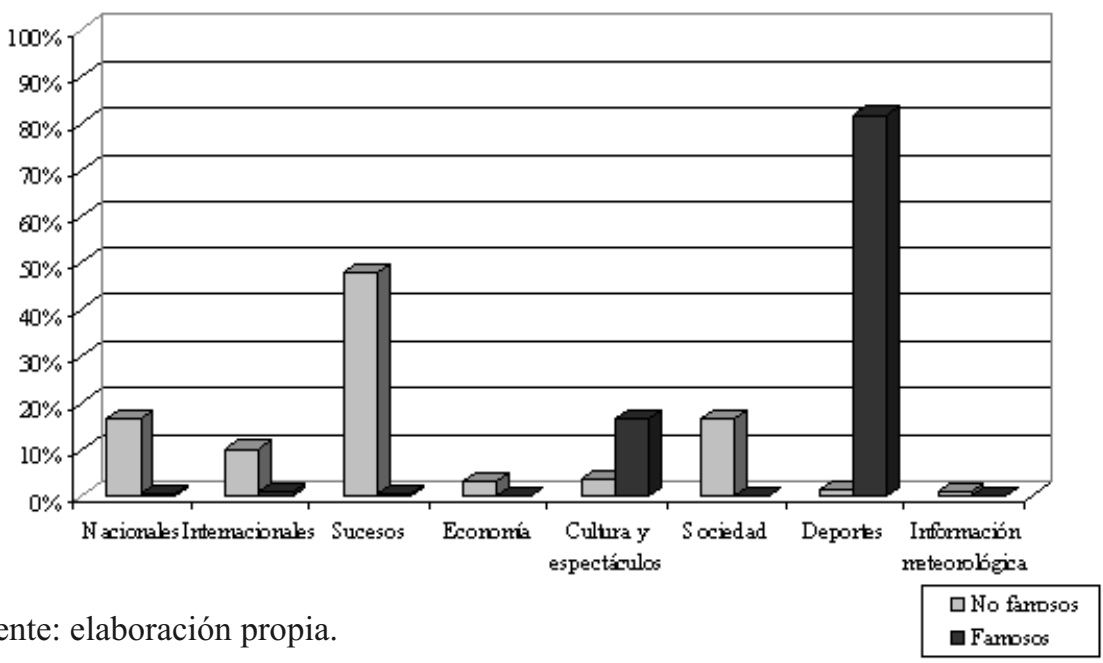

Fuente: elaboración propia.

$\square$ No famosos

Esta limitada temática de las piezas informativas en las que figuraron inmigrantes podría contribuir a crear una imagen sesgada de estos, ya que su participación en la vida pública de la sociedad receptora en la realidad no se limita al deporte de elite, o a su intervención en asuntos conflictivos, aunque esa sea la representación mayoritaria que se ofrece en los programas informativos. De esta manera se sobrerrepresenta un colectivo que es realmente minoritario (tanto los deportistas o artistas famosos, como los no famosos que delinquen o son víctimas) y se omite la participación y aporte cotidiano de las personas de origen extranjero que forman parte de la estructura productiva del país y que comparten su vida social con los autóctonos.

\section{Cómo son los inmigrantes en el género informativo}

Casi tres cuartas partes del tiempo en que figuraron inmigrantes no famosos en el género informativo (74,65\%) estos habían nacido en el continente africano $(26,35 \%)$ o en Centro y Sudamérica (48,30\%). Y en la mayor parte de los minutos analizados $(83,39 \%)$ habían trasladado su residencia a Europa comunitaria. De esta forma, se verifica en ellos el esquema más frecuente de migración económica: pasar de un país menos desarrollado a un país más desarrollado.

Los inmigrantes famosos, en cambio, se presentaron en la mayor parte del tiempo $(60,40 \%)$ en grupos conformados por personas de distintos continentes de nacimiento. Esta circunstancia fue muy frecuente en la sección de deportes $(71,22 \%)$, en la que habitualmente se mostraba en cada secuencia más de un futbolista o jugador de baloncesto de origen extranjero. De los 27 países de nacimiento que aparecieron dentro de esta categoría, diez pertenecieron a Europa comunitaria, seis a América del Centro y del Sur, seis a África, tres a Europa no comunitaria y dos a América del Norte. No existió, por tanto, un marcado predominio de los continentes de menor desarrollo. Asimismo, en un 22,27\% del tiempo en que figuraron inmigrantes famosos estos nacieron en Europa comunitaria 
y en un 14,57\% en América del Centro y del Sur. De esta manera, en el continente de origen sigue sin vislumbrarse con claridad el esquema de migración económica que se dibujó de forma diáfana en el caso de los no famosos. No obstante, en los continentes receptores la tendencia sí fue similar a la de los no famosos: Europa comunitaria fue el más frecuente (82,44\%), seguido en este caso por América del Norte $(15,83 \%)$.

En cuanto a la situación administrativa, solo en los no famosos se presentó el caso de inmigrantes no autorizados legalmente a residir en la sociedad receptora, pero esto solo ocurrió en un $9,60 \%$ del tiempo total en que ellos figuraron. Igualmente, el porcentaje en el que no se pudo determinar este dato fue también mayor en este colectivo, alcanzando un $63,45 \%$. En los famosos, por el contrario, la categoría No consta obtuvo un 1,66\%, porque la información sobre ellos era, por definición, de dominio público.

Esta misma diferencia se repitió en el caso de las razones de emigración, que en los no famosos fueron la mayor parte del tiempo desconocidas $(65,49 \%)$ y en los famosos conocidas (97,02\%). En este último colectivo, sin embargo, destacó sobre todos los motivos el de tener un trabajo seguro en el país receptor $(89,82 \%)$, mientras que esa motivación apenas pudo verificarse en un $6,19 \%$ de los minutos en que figuraron los no famosos. Del escaso tiempo en que se pudieron conocer las razones por las que estos partieron de sus países de origen, la que más frecuentemente apareció fue la crisis económica y social (10,62\% del tiempo total de este grupo).

Como consecuencia lógica de los resultados anteriores, casi todo el tiempo en que figuraron famosos $(99,47 \%)$ estos se sustentaban a través de su trabajo, mientras que los no famosos lo hicieron en apenas un 52,02\%. Estos últimos obtuvieron un alto porcentaje en la categoría No consta en esta variable sobre su fuente de ingresos $(32,74 \%$ frente al $0,53 \%$ de los famosos), pero también en las actividades delictivas como medio para satisfacer sus necesidades básicas $(8,99 \%)$. Asimismo, vivían de las ayudas gubernamentales en un $2,81 \%$ del tiempo en que aparecieron, del aporte de algún miembro de la familia en un $2,39 \%$ y de las ayudas no gubernamentales en un $1,05 \%$. Estas tres categorías estuvieron ausentes en los famosos.

El mismo rasgo delictivo de los no famosos pudo detectarse en la pregunta acerca de los antecedentes penales de los inmigrantes. Las figuras públicas apenas alcanzaron un $0,79 \%$, mientras que los que no eran conocidos obtuvieron un $9,17 \%$. La certeza de que no han cometido nunca delitos, por el contrario, se elevó en los famosos a un $89,73 \%$ del tiempo total en que aparecieron, pero en los que no lo eran fue de $29,40 \%$, por la misma falta de información de la que adoleció este colectivo.

La actividad a la que se dedicaban los inmigrantes corrobora la tendencia manifestada hasta ahora, en la que los famosos principalmente se dedicaban a trabajar $(98,68 \%$ de su tiempo) y los que no lo eran tenían más ocupaciones, aparte de esa (48,58\% de su tiempo trabajaban, $10,57 \%$ se dedicaban a actividades delictivas y $2,56 \%$ estudiaban). En ellos también fue más elevado el porcentaje de la categoría No consta $(30,17 \%$ frente a $0,53 \%$ de los famosos).

Además, la situación laboral fue mejor en los famosos que en los no famosos. Este último grupo se desempeñó en las últimas cinco categorías profesionales (trabajadores en la restauración, agricultores y pescadores, trabajadores de la construcción, operarios de maquinarias y trabajadores no cualificados) en un 55,71\% del tiempo total 
en que figuraron, mientras que las figuras públicas apenas alcanzaron un $0,63 \%$ de sus minutos en dichas categorías. Estos últimos, en cambio, en un $99,37 \%$ de su tiempo se desempeñaron en las cuatro primeras categorías, que incluyen a los efectivos de las Fuerzas Armadas, los directivos de empresas y Administraciones Públicas, técnicos y profesionales científicos e intelectuales, y técnicos y profesionales de apoyo. Los no famosos, en cambio, solo pertenecieron a estas profesiones en un 33,02\%.

Gráfico 2: Comparación de cómo son los inmigrantes famosos y los no famosos en los programas informativos analizados

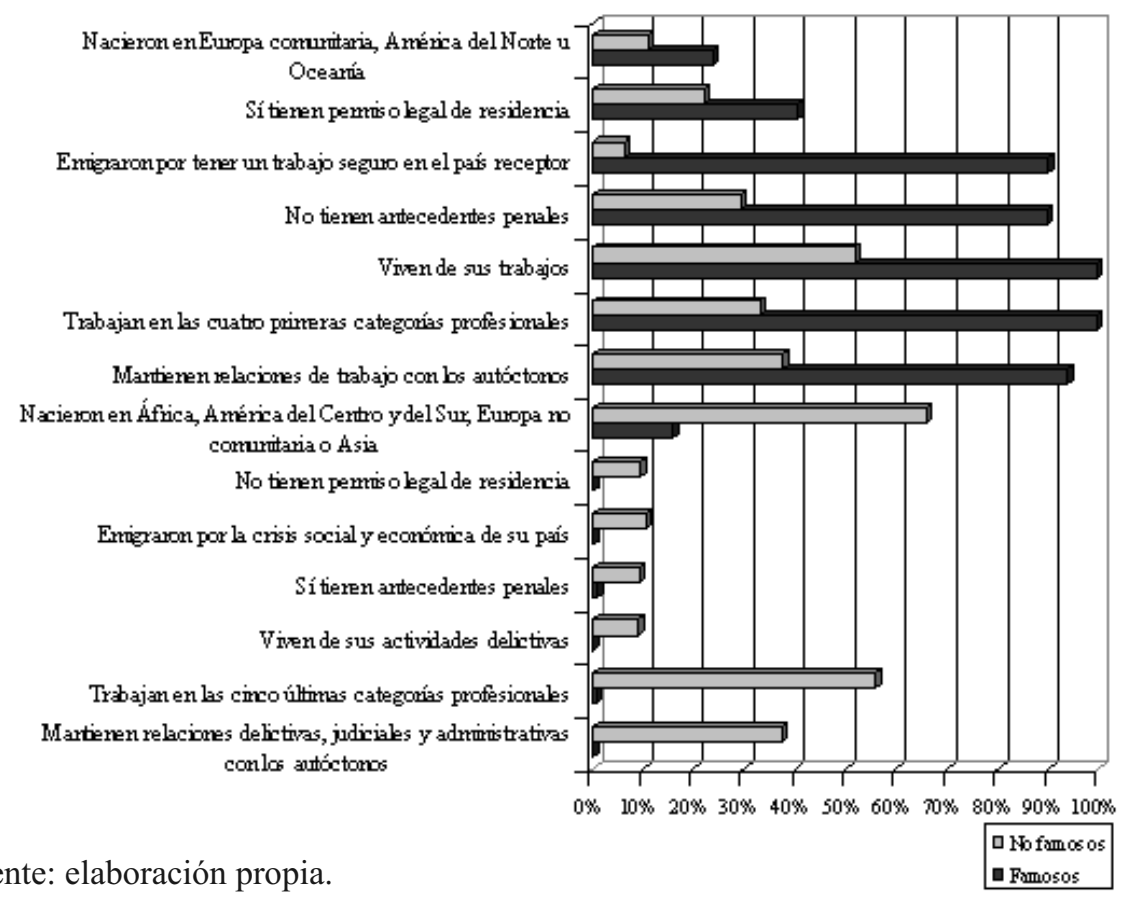

Fuente: elaboración propia.

En las relaciones sociales con los autóctonos también se manifiesta que el aspecto más resaltado de los famosos es su trabajo: un $93,78 \%$ de sus vínculos con los nativos transcurren en este ámbito, mientras que en los no famosos apenas en un 37,58\%. En estos últimos se producen otros tipos de relación: judiciales, es decir, las que se desarrollan en los tribunales, en juicios, o en asuntos relacionados con la administración de justicia (16,98\%); amistosas $(6,62 \%)$; de pareja o familiares $(5,57 \%)$; administrativas o relacionadas con la regularización de su situación legal $(5,28 \%)$; de recepción de ayudas caritativas $(4,30 \%)$ y delictivas, esto es, las que tienen que ver con la planificación y ejecución de actividades tipificadas como ilegales (3,98\%). En este sentido, aunque sigue existiendo una importante relación de los inmigrantes no famosos con el delito, destaca también su vinculación con las personas nacidas en la sociedad receptora más allá de lo laboral, lo que no se pone de relieve en el caso de los famosos. 


\section{La importancia de los inmigrantes y sus características en los programas in- formativos}

Los inmigrantes famosos aparecieron en los titulares del programa informativo con una frecuencia superior a los inmigrantes no famosos $(54,29 \%$ frente a $44,01 \%)$. No obstante, según el orden en el que fueron narrados esos titulares se le otorgó mayor importancia a las piezas periodísticas en las que figuraron personas desconocidas: un $68,16 \%$ de su tiempo total ocuparon del primer al quinto lugar. En cambio, un 75,94\% de los minutos en que aparecieron o se mencionaron famosos aparecieron después del quinto titular. Esta diferencia se debe, principalmente, a que los titulares sobre deportes y cultura suelen ser los últimos y los de sucesos, nacionales y sociedad, los primeros.

Para estudiar la dimensión de lo que es importante en los mensajes televisivos se indagó también en los aspectos que más se destacaron de los inmigrantes cuando aparecieron o se mencionaron. Las actividades que más realizaron en pantalla y sus características más frecuentemente descritas ayudaron a definirlos.

Como se desprende del epígrafe anterior, lo que más se valoró en los inmigrantes famosos fue su trabajo. Por esa razón fue la acción que más realizaron mientras aparecieron $(50,52 \%)$ y el aspecto que más habitualmente fue descrito $(45,23 \%)$, seguido por su físico $(25,89 \%)$, su personalidad $(12,75 \%)$ y sus actividades culturales o artísticas $(5,09 \%)$.

En los inmigrantes no famosos existió una ponderación distinta. En un 30,03\% del tiempo en que figuraron no aparecieron en pantalla, sino que solo se les mencionó. Esta categoría en los famosos apenas alcanzó un 7,27\%, porque a ellos se les mostró con mayor frecuencia. Por eso también el físico de los no famosos fue descrito en un $19,88 \%$, más de seis puntos porcentuales por debajo de las figuras públicas. Únicamente aparecieron trabajando un $13,29 \%$, y sus actividades laborales y académicas fueron descritas en un $13,80 \%$. Realizaron Otras acciones no definidas en las categorías de la ficha de análisis en un $29,22 \%$ del tiempo en que figuraron, en un $8,97 \%$ mantuvieron relaciones personales, en un 6,27\% realizaron actos delictivos, en un $3,32 \%$ realizaron actividades políticas y en un $2,88 \%$ intentaron resolver necesidades derivadas de su proceso migratorio.

Por otro lado, se describieron: su personalidad en un 14,07\%; su lugar de procedencia en un $10,67 \%$; sus actividades delictivas en un $9,62 \%$; su proceso de adaptación en un $5,67 \%$; sus necesidades económicas en un $4,20 \%$; su estado de salud en un $2,81 \%$; sus intenciones de permanencia en un 2,66\%; sus antecedentes penales en un $2,42 \%$ y otros aspectos en el restante $9,57 \%$ del tiempo en que se mostraron características de este colectivo.

De modo que los aspectos en los que se enfocó la atención de los informativos fueron más variados en los inmigrantes que no eran figuras públicas, aunque existió una tendencia a resaltar sus relaciones y su personalidad, su inclinación delictiva, sus dificultades económicas y de adaptación, y su lugar de procedencia. 
Gráfico 3: Comparación de los aspectos a los que se les otorga mayor importancia en los inmigrantes famosos y no famosos en los programas informativos analizados

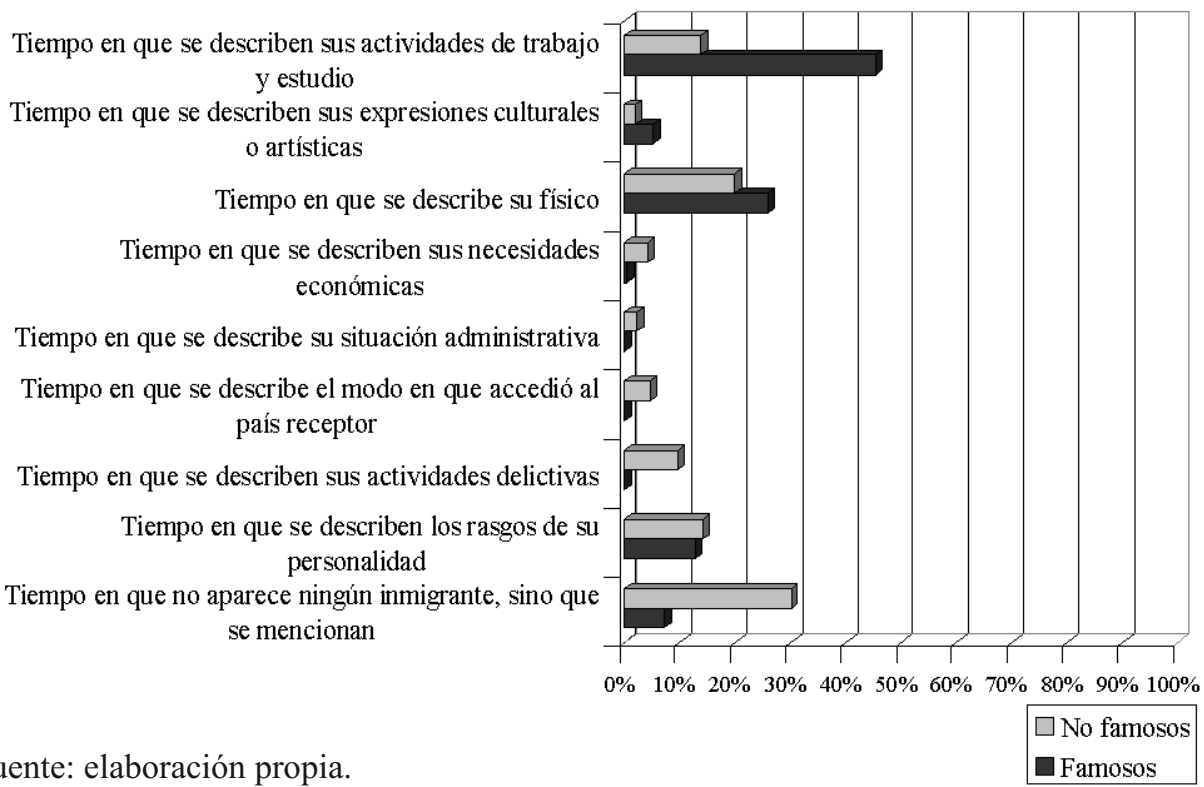

\section{Valoración de los inmigrantes en el género informativo}

Para estudiar los juicios de valoración emitidos hacia los inmigrantes que aparecieron o se mencionaron en los programas informativos analizados se analizaron sus actitudes, comportamientos y lenguaje para definir sus características, de clara tendencia positiva o negativa. La manera de presentar las preguntas de esta parte en pares opuestos (agresivos o pacíficos, cumplidores o quebrantadores de la ley, autosuficientes o indefensos, sanos o enfermos, etc.) se debió a la necesidad de que las categorías fueran excluyentes entre sí, y ello solo podía lograrse preguntando exclusivamente por una sola característica de los inmigrantes representados y ofreciendo dos opciones que no podían encontrarse simultáneamente en la misma secuencia. Solo cabían las alternativas de poseer esa característica, de no poseerla o de que no se ofreciera ninguna información sobre ella.

En este bloque de la ficha de análisis se comprobó que la imagen de los inmigrantes no famosos estuvo vinculada a los delitos y la falta de respeto por la ley, no en vano estos figuraron la mayor parte del tiempo en la sección de sucesos. Así, en ellos fue mayor que en los famosos la proporción de tiempo en que se comportaron o hablaron de forma agresiva (6,53\%); quebrantaron la ley o manifestaron su intención de hacerlo $(27,54 \%)$; tuvieron relaciones con la población nativa en las que predominó la agresividad (11,03\%); y demostraron ser culturalmente incompatibles con la población autóctona $(15,77 \%)$, entendiendo por compatibilidad la capacidad de convivencia armónica, y de entendimiento, relación e intercambio social no conflictivo. Estas mismas categorías, en cambio, no superaron en ninguno de los casos el 1\% del tiempo en que figuraron inmigrantes famosos. 
De esta forma, la imagen de los inmigrantes no famosos se vinculó a los problemas, pero no solo a los que causaron, sino a los que tuvieron que sobrellevar. En mayor porcentaje de tiempo que las figuras públicas fueron víctimas $(15,03 \%)$, es decir, sufrieron perjuicios materiales, físicos o morales por actuaciones de otras personas con las que tuvieron relación. Además, la forma en la que afrontaron esas y otras dificultades no siempre fue satisfactoria, por eso en un 5,83\% del tiempo en que aparecieron o se mencionaron, se mostraron dependientes de otras personas o indefensos, incapaces de resolver las situaciones por sí mismos. También sufrieron enfermedades $(3,79 \%)$, tuvieron un accidente $(2,99 \%)$ y estuvieron muertos $(5,34 \%)$ en mayor proporción de minutos que los famosos. Este último grupo no superó un 1,3\% en ninguna de las categorías mencionadas.

Los inmigrantes que eran figuras públicas, sin embargo, fueron representados como pacíficos $(94,06 \%)$, cumplidores de las leyes $(93,09 \%)$, culturalmente compatibles $(83,54 \%)$, autosuficientes $(99,31 \%)$ y con un buen estado de salud $(89,98 \%)$ la mayor parte del tiempo. Estos porcentajes fueron menores en los no famosos, como se observa en el gráfico siguiente.

Gráfico 4: Comparación de algunos aspectos de la valoración de los inmigrantes famosos y no famosos en los programas informativos analizados

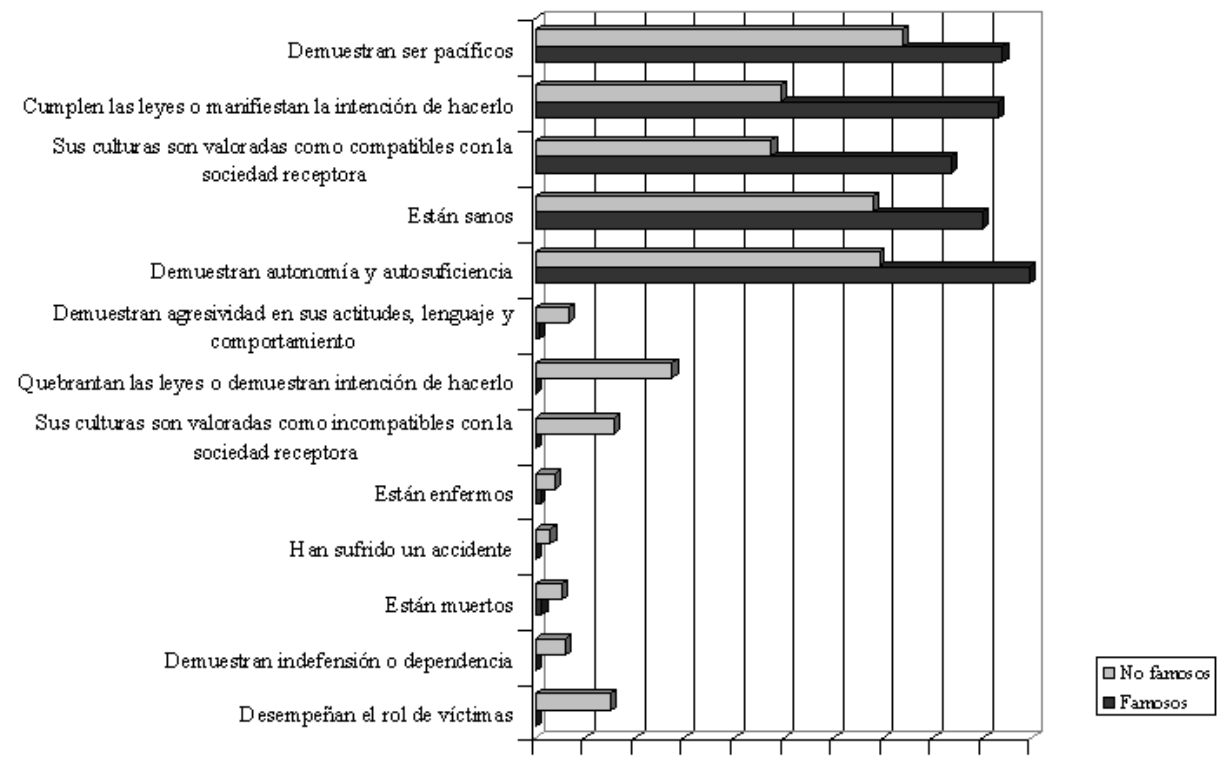

Fuente: elaboración propia.

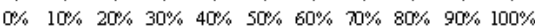

\section{Temas frecuentemente relacionados con los inmigrantes}

La televisión es un medio que transmite valoraciones no solo a través de las características positivas o negativas que otorga a las personas, sino por la vinculación que es capaz de conseguir entre dos temas aparentemente inconexos. La frecuente aparición de dos elementos dentro de la misma secuencia puede llegar a ocasionar que la audiencia llegue a relacionarlos. Por eso, resultaba importante indagar qué temas salían a colación co- 
múnmente cuando en la pantalla chica eran representados inmigrantes, pues la imagen de estos se construye también a través de los conceptos a los que se les vincula.

Respecto al grupo de los famosos, lo primero que es necesario destacar es que el tiempo total en el que aparecieron o se mencionaron apenas se les vinculó a los tópicos estudiados. El único que superó el 0,50\%, alcanzando un escaso $2,10 \%$, fue el de los aportes y riquezas de la diversidad cultural. De esta forma, este colectivo estuvo alejado de los lugares comunes en los que se basa el rechazo a la inmigración: aumento de la inseguridad, drogas, policía, ayuda humanitaria, escasez de recursos, etc. Por el contrario, se les relacionó con un importante aporte para la sociedad, por lo que su valoración, en este sentido, fue nuevamente positiva.

En todos los demás temas el grupo de los no famosos superó al de los famosos, tanto en términos absolutos como relativos: aumento de la delincuencia y la inseguridad $(29,12 \%)$, aparición o actuación de la policía $(15,31 \%)$, ayudas solidarias o humanitarias $(8,92 \%)$, pobreza de los países subdesarrollados $(6,92 \%)$, crisis económica $(6,11 \%)$, droga y narcotráfico $(4,78 \%)$, escasez de espacio y de recursos $(2,25 \%)$ y violencia de género $(3,79 \%)$. Todos estos temas tienen una connotación negativa y los que más frecuentemente aparecieron estuvieron relacionados con el incumplimiento de la ley: la policía y el aumento de la inseguridad, alcanzando este último cerca de una tercera parte del tiempo total de este colectivo.

Esta coincidencia en la misma secuencia de los inmigrantes no famosos y del tratamiento del tema de la inseguridad refuerza la tendencia obtenida en los resultados anteriores: una vinculación de este grupo de personas nacidas en el extranjero con el incumplimiento de la ley y con la generación de problemas en el país receptor.

Esta imagen conflictiva fue subrayada por la mayor frecuencia de aparición de temas como las drogas o la violencia de género, aunque dichos resultados no hayan ofrecido cifras especialmente altas. Por otro lado, los problemas económicos y la necesidad de recurrir a ayudas humanitarias también refuerzan esa idea de falta de autonomía, pobreza e indefensión que se ha señalado en anteriores epígrafes como característica de los no famosos. Y el tópico de la falta de recursos y de espacio también corrobora la valo-

Gráfico 5: Comparación de la frecuencia en que fueron mostrados o mencionados algunos temas en la misma secuencia que los inmigrantes famosos y no famosos

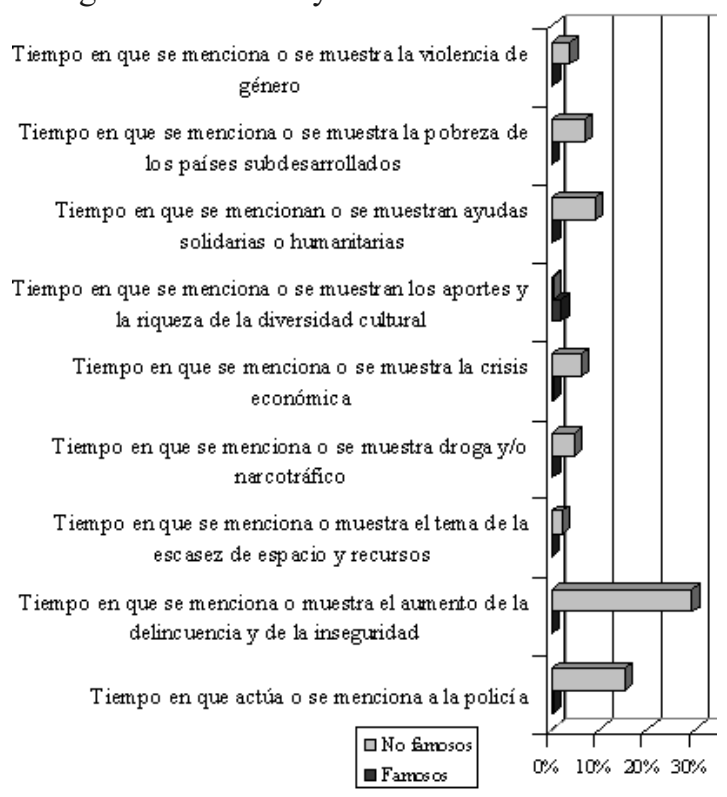

Fuente: elaboración propia. 
ración negativa del colectivo, relacionado más frecuentemente con las pérdidas que ocasiona a la sociedad receptora que con las ganancias que le puede ofrecer.

\section{Conclusiones}

Los resultados de la investigación revelaron que los programas informativos estudiados tienen una tendencia a vincular a los inmigrantes no famosos con la delincuencia y la falta de respeto por la ley. La mayor parte del tiempo aparecieron o se mencionaron en la sección de sucesos y con una frecuencia relativamente elevada quebrantaron la ley o manifestaron su intención de hacerlo, tuvieron como fuente de ingresos las actividades ilegales, y fueron agresivos. También desempeñaron el rol de víctimas y se mostraron dependientes o indefensos en mayor porcentaje de minutos que los inmigrantes famosos y la importancia que se le otorgó a su faceta laboral no fue tan marcada como en dicho grupo. Cuando este colectivo apareció en pantalla, en un alto porcentaje de tiempo se trató simultáneamente el tema del aumento de la inseguridad y se mostraron o mencionaron policías y otras fuerzas de seguridad del Estado. En resumen, la imagen de las personas de origen extranjero que no eran figuras públicas se relacionó con problemas sociales y delincuencia, como se había previsto en las hipótesis.

Por su parte, los inmigrantes famosos tuvieron mejores condiciones laborales que los no famosos y su trabajo fue el aspecto al que más importancia se le otorgó. Asimismo, las relaciones sociales de este grupo con la población autóctona se desarrollaron la mayor parte del tiempo en el ámbito laboral, mientras que las personas de origen extranjero que no eran figuras públicas mostraron una mayor variedad de vínculos con los nativos, algunos de ellos relacionados con su destacada actividad delictiva. Los famosos, a pesar de las limitadas relaciones afectivos con los nativos que se mostraron, tuvieron la mayor parte del tiempo actitudes, comportamientos y lenguaje propicios para su integración armónica a la sociedad receptora: fueron pacíficos, cumplidores de la ley y autosuficientes. Los tópicos sobre la inmigración: delincuencia, drogas, cruce ilegal de fronteras, inseguridad, etc., apenas fueron abordados cuando aparecieron. De esta manera, la valoración de los inmigrantes famosos fue mayoritariamente positiva, tal como se esperaba al formular las hipótesis de este estudio.

Estas marcadas diferencias entre famosos y no famosos, comprobadas por esta investigación, podrían crear una imagen en cierta forma bipolar de los inmigrantes y de lo que aportan a la sociedad. De un lado los deportistas de elite, que emigran a los países desarrollados y juegan en sus equipos, de fútbol principalmente, haciéndoles obtener buenos resultados y consiguiendo ellos a la vez unas remuneraciones nada despreciables. Y, de otro lado, los inmigrantes que vienen a los países desarrollados a traer problemas: robos, asesinatos, narcotráfico, cruce ilegal de fronteras, en los que participan o de los que son víctimas, obteniendo de la sociedad receptora solo los castigos dispuestos por la ley o la atención básica que requieren los afectados por estos delitos. La realidad es mucho más compleja que esta imagen televisiva. La representación mediática sobrevalora una realidad minoritaria y oculta otras situaciones cotidianas en las que participan inmigrantes con mayor frecuencia y que también podrían ser objeto de tratamiento periodístico.

Esta representación sesgada de los inmigrantes puede influir en la imagen que tiene de ellos la población autóctona, puesto que la televisión contribuye en buena medida 
a la conformación de las nociones compartidas sobre la realidad. Esta distorsión de las verdaderas características de las personas de origen extranjero podría también condicionar la disposición de los nativos a colaborar en su integración, porque en el caso de los no famosos los presenta como individuos que vienen a traer problemas al país, y en el de los no famosos los aparta de la cotidianidad del intercambio social, al pertenecer a una elite o minoría en este caso sobrerrepresentada. En ninguno de los dos grupos se proyecta la idea del inmigrante con el que día a día existe relación, al que se le brinda ayuda y del que se obtiene también colaboración, sino que se recalca una noción lejana, ajena, que involucra en una medida muy pequeña a los autóctonos con ellos y en la que no existe intercambio y cooperación mutuos.

Una visión más ajustada a la realidad y en la que se valoraran positivamente los aportes de la inmigración facilitaría su aceptación por parte de la población autóctona, su tratamiento igualitario y su intercambio social y cultural fluido, factores imprescindibles para la construcción de una sociedad intercultural.

\section{Referencias bibliográficas}

ARDEVOL ABREU, Alberto (2008): "La inmigración, en la fotografía de prensa de Canarias". Revista Latina de Comunicación Social, $\mathrm{n}^{\circ}$ 63. La Laguna (Tenerife), Universidad de La Laguna, en línea en http://www.ull.es/publicaciones/latina /08/34_791_54_fotoperiodismo/Alberto_Ardevol.html (19-10-08).

BARROSO GARCÍA, Jaime (1996): Realización de los géneros televisivos. Madrid, Síntesis.

CASERO RIPOLLÉS, Andreu (2003): "Sin papeles: La identidad de los inmigrantes de los medios de comunicación", en SAMPEDRO, Víctor Francisco (ed.): La pantalla de las identidades: medios de comunicación, políticas y mercados de identidad. Barcelona, Icaria, pp. 233-257.

CEA D'ANCONA, Ma Ángeles y VALLES MARTÍNEZ, Miguel (2008): Evolución del racismo y la xenofobia en España. Informe 2008. Madrid, Ministerio del Trabajo e Inmigración.

CIS CENTRO DE INVESTIGACIONES SOCIOLÓGICAS (2009): Estudio 2817. Actitudes ante la inmigración (III). Madrid, en línea en http://www.cis.es/cis /opencms/Archivos/Marginales/2800_2819/2817/e281700.html (09-02-10).

GALÁN FAJARDO, Elena (2006): "La representación de los inmigrantes en la ficción televisiva en España. Propuesta para un análisis de contenido. El Comisario y Hospital Central". Revista Latina de Comunicación Social, $\mathrm{n}^{\mathrm{0}}$ 61. La Laguna, Universidad de La Laguna, en línea en http://www.ull.es/publicaciones/latina /200608galan.htm (15-01-08).

GARCÍA CASTAÑO, E. Javier; GRANADOS MARTÍNEZ, Antolín; y CAPELLÁN DE TORO, Lorenzo (2003): "Presencia e imagen de la inmigración extranjera en Andalucía", en AUBARELL, Gemma (dir.): Perspectivas de la inmigración en España. Una aproximación desde el territorio. Barcelona, Icaria, pp. 81-127. 
GARRETA BOCHACA, Jordi (2003): La integración sociocultural de las minorías étnicas (gitanos e inmigrantes). Barcelona, Anthropos.

GERBNER, George (1969): “Toward 'Cultural Indicators': The Analysis of Mass Mediated Public Message System", en The Analysis of Communication Content: Developments in Scientific Theories and Computer Techniques. New York, John Wiley \& Sons, pp. 123-132.

HUMANES, María Luisa (2001): "El encuadre mediático de la realidad social. Un análisis de los contenidos informativos en televisión". Zer. Revista de estudios de comunicación, $\mathrm{n}^{\circ}$ 11. Bizkaia, Universidad del País Vasco, pp. 119-141.

IMBERT, Gérard (2003): El zoo visual. De la televisión espectacular a la televisión especular. Barcelona, Gedisa.

LACALLE, Charo (2008): El discurso televisivo sobre la inmigración. Ficción y construcción de identidad. Barcelona, Omega.

LORITE GARCÍA, Nicolás (dir., 2004): Tratamiento informativo de la inmigración en España 2002. Madrid, Ministerio del Trabajo, en línea en http://www.oberaxemtas.upcomillas.es/Publicaciones/Libros/tratamiento/tratamiento.htm.

MARQUÉS DÍEZ, Bárbara (2000): Las dificultades psicológicas de adaptación de los trabajadores inmigrantes. Informe sobre investigaciones y experiencias en España y Alemania. Zaragoza, Confederación de Empresarios de Aragón.

MERINO ARRIBAS, María Adoración (2009): Inmigración irregular africana y prensa en Canarias (1999-2003). Santa Cruz de Tenerife, Ediciones Idea.

MORGAN, Michael y SHANAHAN, James (2010): "The State of Cultivation". Journal of Broadcasting \& Electronic Media, 54 (2). Philadelphia, Broadcast Education Association, pp. 337-355.

MUÑIZ, Carlos e IGARTUA, Juan José (2004): "Encuadres noticiosos e inmigración. Un análisis de contenido de la prensa y televisión española". Zer. Revista de estudios de comunicación, $\mathrm{n}^{\circ}$ 16. Bizkaia, Universidad del País Vasco, en línea en http://www.ehu.es/zer/zer16/articulo6.htm (10-12-05).

NAÏR, Sami (2006): Y vendrán... las migraciones en tiempos hostiles. Barcelona, Planeta.

NOELLE-NEUMANN, Elisabeth (1995): La espiral del silencio. Opinión pública: nuestra piel social. Barcelona, Paidós.

PABLOS COELLO, José Manuel de y ARDEBOL ABREU, Alberto (2008): "Medios de comunicación social", en CABRERA PÉREZ, Lidia (coord.): La integración cultural y social de los inmigrantes latinoamericanos: Inquietudes y sugerencias para políticas de cambio. Madrid, Universitas, pp. 167-194.

PAJARES, Miguel (2005): La integración ciudadana. Una perspectiva para la inmigración. Barcelona, Icaria. 
RODA FERNÁNDEZ, Rafael (2001): Medios de comunicación de masas. Su influencia en la sociedad y en la cultura contemporáneas. Madrid, Centro de Investigaciones Sociológicas y Siglo XXI.

RODRÍGUEZ BORGES, Fidel F. (2010): "Discurso xenófobo y fijación de agenda. Un estudio de caso en la prensa de Canarias (España)". Revista Latina de Comunicación Social, $\mathrm{n}^{\circ}$ 65. La Laguna (Tenerife), Universidad de La Laguna, pp. 222230, en línea en: en línea en http://www.revistalatinacs.org/10/art2/895 ULL/17_Rodrigo.html (27-11-10).

RODRÍGUEZ BREIJO, Vanessa (2010): El fenómeno de la inmigración en televisión. Contribución mediática a la construcción de una sociedad intercultural. Tesis doctoral, Universidad de La Laguna.

RODRÍGUEZ DÍAZ, Raquel y MENA MONTES, Noemí (2008): “Opinión Pública y frames: La crisis de los cayucos". Revista Latina de Comunicación Social, $\mathrm{n}^{\circ} 63$. La Laguna (Tenerife), Universidad de La Laguna, en línea en http://www.ull.es/publicaciones/latina/08/28_46_Vicalvaro/Raquel_Rodriguez_y_Noemi_Mena.html (19-10-09).

ROSTECKA, Bárbara (2005): "Proceso social de la inmigración no autorizada", en GODENAU, Dirk y ZAPATA HERNÁNDEZ, Vicente Manuel (coords.): La inmigración irregular. Aproximación multidisciplinar. Santa Cruz de Tenerife, Cabildo de Tenerife, pp. 185-210.

SABÉS TURMO, Fernando (2010): "Análisis del tratamiento del fenómeno migratorio en www.elpais.com". Revista Latina de Comunicación Social, $\mathrm{n}^{\circ}$ 65, La Laguna (Tenerife), Universidad de La Laguna, pp. 30-44, en línea en http://www.revistalatinacs.org/10/art/881_UAB/03_Sabes.html (12-02-10).

SANABRIA, Francisco (1994): Información audiovisual. Teoría y técnica de la información radiofónica y televisiva. Barcelona, Bosch.

SHANAHAN, James y MORGAN, Michael (1999): Television and its Viewers. Cultivation Theory and Research. United Kingdom, Cambridge University Press.

SIERRA BRAVO, Restituto (1999): Técnicas de investigación social. Teoría y ejercicios. Madrid, Paraninfo.

SOENGAS, Xosé (2008): El enfoque informativo. Los puntos de vista de una noticia en televisión. Sevilla, Laberinto.

TNS (2008): Informe de la audiencia media y porcentual de los programas emitidos en cadenas nacionales y autonómicas para el periodo del 8 al 14 de enero de 2008 en Tenerife, facilitados especialmente para el desarrollo de esta investigación.

VILCHES, Lorenzo (1993): La televisión. Los efectos del bien y del mal. Barcelona, Paidós.

VILLAFAÑE, Justo y MÍNGUEZ, Norberto (1996): Principios de teoría general de la imagen. Madrid, Pirámide.

ZAPATA-BARRERO, Ricard (2009): Fundamentos de los discursos politicos en torno a la inmigración. Madrid, Trotta. 